INTERNATIONAL DESIGN CONFERENCE - DESIGN 2018

https://doi.org/10.21278/idc.2018.0326

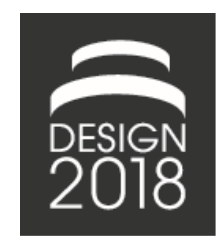

\title{
MODEL-DRIVEN DECISION ARENA: AN AEROSPACE CASE STUDY
}

\author{
M. Bertoni, J. Wall and A. Bertoni
}

\begin{abstract}
The concept of Decision Theatre (DT) is of great interest to leverage knowledge sharing in early stage design decision events. Yet, few contributions show how to configure a DT to support design space exploration and concept selection in cross-functional teams. This paper describes the development of a model-driven decision arena (MDDA) for aero-engine sub-system design. After presenting the descriptive study findings, it illustrates the overall logic of the MDDA environment and exemplifies its use in a case study related to the design of a turbine real structure (TRS) for commercial use.
\end{abstract}

Keywords: decision theatre, visualisation, case study, value driven design, collaborative design

\section{Introduction}

Engineering design is not and cannot be a purely technical activity: whatever technical work is done it must necessarily be done in a social context - a context that encompasses the ordinary practical decisionmaking processes (Larsson et al., 2010). This issue is emphasized when companies move towards an extended business model, focusing on 'sale of use' rather than 'sale of product', such as the TotalCare ${ }^{\circledR}$ offer from the aero-engine manufacturer Rolls-Royce (Harrison, 2006). Development of 'functions', rather than 'hardware', as part of total life-cycle commitments radically changes scope and objectives of engineering activities. To provide products or functions that truly meet the full range of life-cycle demands and needs, it is important to make downstream knowledge available as early as possible in the design process. This entails inviting several disciplines and domains to early stage decision events, which is to take collaborative decisions in a cross-functional team setting.

Design work can be therefore understood as a socio-technical business in "the debates about whether the design is 'done', if the specifications have been 'met' and if the result is 'good." (Minneman, 1991, p. 63). Hence, the concept of Decision Theatre (DT) is of great interest to leverage communication and knowledge sharing in these events, improving timeliness and quality of design decisions. Research on DT environments features several examples, from water resource (e.g. Sampson et al., 2011) to energy (e.g. Fan et al., 2012) management. A DT typically consists of a high-speed server with large fixed screens on which to display complex data, models and simulation results. Its purpose is to facilitate collaborative decision-making in complex, multi-disciplinary and uncertain situations. This common understanding is achieved by creating a visual model of what each actor needs to know to deliberate about a given situation, showing rationale, origin, and connections between different sources of information. Yet, few contributions address the issue of how a DT shall be designed and customized to support cross-functional teams in dealing with early stage design decisions. A question remains concerning how individuals from different functions and roles can take advantage of $3 \mathrm{D}$ visualizations, 
simulation models, and other computer-assisted tools, to collect participants' input and knowledge, to ultimately improve decision making in design.

The purpose of this research is to develop a model-driven decision arena (MDDA) to support early stage design concept exploration. The objective of this paper is to describe how the MDDA was developed for the design of an aero-engine component for commercial use. The manuscript initially describes the findings of the descriptive study, focusing on the engineering need of design support in the earliest phases of aero-engine sub-system design. It further describes the overall logic of the MDDA environment, which is how it guides the team in exploring the design space, both from a qualitative and quantitative point of view. Eventually, the paper displays the current MDDA implementation in the described case study and discusses challenges and opportunities for improvement.

\section{Methodology}

The paper presents the findings of applied research based on a single case study approach (Yin, 2013). The case study company is active on the global market as a design-make supplier to major aero-engine manufacturers, in various product and technology development projects, mainly for gas turbines, aircraft, and rocket engines. It functions as an independent risk and revenue sharing partner, and assumes responsibility for certain engine components, from development, design, and manufacturing, to repair and maintenance services throughout the entire lifetime of an engine type.

Action Research (AR) (Avison et al., 1999) best describes how the research was conducted. AR is an iterative process involving researchers and practitioners working together on a cycle of activities, including problem diagnosis, intervention and reflective learning (Coughlan and Coghlan, 2002). It involves a spiral of routines, look-think-act or learning circles, in which researchers test a theory with practitioners in real situations, gain feedback from this experience, modify the theory because of this feedback, then try again (Avison et al., 1999). Empirical data were collected through semi-structured interviews with managers, engineers and information technology experts involved in the development of hardware and services related to aerospace products. Reflective learning was aided by the continuous participation in regular debriefing activities, which took the form of regular (bi-weekly) virtual meetings. Compiling visual representations and demonstrators of the emerging modeling concepts was an important means to validate techniques with stakeholders, and to identify critical topics for modeling.

\section{Model-driven decision support for early stage design}

\subsection{Frontloading engineering design activities with models}

The Basic Design Cycle proposed by Roosenburg and Eekels (1995) illustrates the iterative nature of the engineering design process decision making. Here engineers apply different types of models to play with design parameters settings and to assess expected properties of a design before a decision. An important part of the design process is exploration, where insights are gained by unveiling behavior and constraints through experimentation. However, manually performed what-if analyses prohibit extensive exploration of a vast design space, thus structured and automated approaches are needed.

The evolution of computational software has brought to the exponential growth in the use of virtual models for performance analysis and optimization (e.g., Computational Fluid Dynamics, Multibody Dynamics, etc.). Vallhagen et al. (2013) show how virtual modeling methods are becoming a commodity in aerospace sub-system design, mainly in the domain of structural mechanics, aerothermodynamics, and fluid mechanics. Runnemalm et al. (2009), for instance, exploit simulations already at a conceptual design stage to assess the effect of welding on distortions and induced stresses in the product. Söderberg et al. (2006) even consider a whole life-cycle in the design exploration activity, developing practices and models for geometrical robustness simulations.

However, the 'frontloading' exercise (Thomke and Fujimoto, 2000) implies a change in the way simulations are used to support new product development, from verifying if a product does not fail regarding performance to guiding on 'what' to develop since an early stage (Isaksson et al., 2009). Isaksson et al. (2015) further acknowledge the important role of virtual verification and multidisciplinary optimization, stressing the need for a broader view on how virtual models can be used to support conceptual decisions, from early product positioning to the definition of a program's high- 
level objectives, to architectural design choices. This calls for design decision support environments that, early in the design process, raises awareness about the vastity of the feasible design space. Also, it shall provide the necessary contextual knowledge to orient trade-off resolution, not only looking at the design of the technical hardware but at the entire system of products and services (Bertoni et al., 2016).

\subsection{Models for designing value-adding systems}

Lean product development (e.g., Siyam et al., 2015), Product Service System (e.g., Baines et al., 2007) and Systems Engineering (SE) (e.g., Weiss, 2013) researchers agree on the centrality of the "value" concept to support early stage design decisions for complex systems. In the words of Hazelrigg (1988), "Values tell engineers what you want. Requirements only tell them what you don't want".

Designing value-added systems means for practitioners to look at design trade-offs from the perspective of how much customers 'value' certain capabilities against each other (Isaksson et al., 2015). The research stream of Value Driven Design (VDD) (Collopy and Hollingsworth, 2011) identifies possible modeling approaches for value. VDD exploits quantitative analytical models to perform tradespace studies on alternative design configurations (e.g., McManus, 2007), so to enable optimization of the different parts of the sub-system. Intuitively, these models take the form of monetary optimization functions (Price et al., 2012) based on Net Present Value (NPV) or Surplus Value (SV) approaches, the latter often being used as surrogate object for long-term profitability associated with a given design concept (see: Curran et al., 2010; Fanthorpe et al., 2011; Cheung et al., 2012). The main argument in favor of a VDD approach is found in several case studies from SE research (see Collopy, 2012; Gorissen et al., 2014) that shows how requirements hinder a systematic exploration of design alternatives, causing the most valuable ones to be rarely identified. More recent contributions exploit qualitative value models, in the attempt to improve communication among decision makers (Collopy, 2012; Soban et al., 2012, Isaksson et al., 2013). Mixing qualitative and quantitative data is claimed to mitigate the risk of focusing only on the nearest customer, which is that of targeting local optimal solutions that do not add value from a more system-level perspective (Bertoni et al., 2016). Qualitative models also assist engineers in maintaining the link between system representation and design intent when requirements are decomposed and allocated to various sub-system owners. Importantly, the choice to use qualitative or quantitative models is driven by the specific 'value stream' a design decision belongs to. Kennedy et al. (2008) identifies 2 separate streams, which are the Knowledge Value Stream (KVS) and the Product Value Stream (PVS). The KVS represents the capture and reuse of knowledge about markets, customers, technologies, products and manufacturing capabilities across projects and organizations. The PVS is specific for each project and consists of the flow of tasks, people, and equipment needed for creating, for example, drawings, bill of materials and manufacturing systems.

\subsection{Information visualization in early design}

By exercising both qualitative and quantitative models the design team can improve the way contextual design information is captured during the requirements decomposition process, raising awareness of the system-level effects triggered by a specific design variation. This mixed-use increases the level of complexity of the analysis, requiring engineers and decision makers to deal more inputs when making decisions. Visual representations play an important role in the design activity, to synthesize such heterogeneous inputs and to build mental models when searching for solutions (Endsley, 1995) while avoiding the risk of information overload (Tegarden, 1999). Literature shows several cases proving the effectiveness of information visualization in decision processes (e.g., Dull and Tegarden, 1999; Bresciani and Eppler, 2009). The root cause of this success can be traced back to the 'theory of cuesummation'. This states that the use of multiple cues enhances associative processing and mitigating information overload if different information channels are not filled in by too much information (Severin, 1967).

Another important finding concerns the need of displaying information in an environment that is familiar to designers and engineers. This helps in limiting the reluctance towards new methods typical of established engineering environment (Sedlmair et al., 2011), and in enhancing the way individuals understand the system intent, thus improving the collaborative decision-making process. Visualizing value properly, by placing it in the right context and by highlighting the relationship with the other 
design information, is an important step to drive concept selection activities at the decision gate towards value-robust solutions. Here decision makers require methods and tools that allow for a streamlined navigation through product structures, relationships, and query results, to faster information consumption and interpretation, ultimately exploiting associative processing to enable the most informed and robust decisions possible.

\section{Model-driven decision arena: An aerospace application}

The successful deployment of model-driven support for decision making needs to account for issues and phenomena described above, hence creating an environment where individuals can link "value" to product components requirements information, technical performances and cost. Furthermore, the crossfunctional team members shall be able to understand and interact with the outcome of the modeling activity, so to evaluate options, assess changes and share knowledge that is not domain or discipline specific. Figure 1 describes the high-level logic of the proposed arena environment. The MDDA is intended to support decisions in the KVS, for an early-stage down selection of technologies, as well as in the PVS, for further evaluation of technology platform configurations in a Design of Experiment loop.
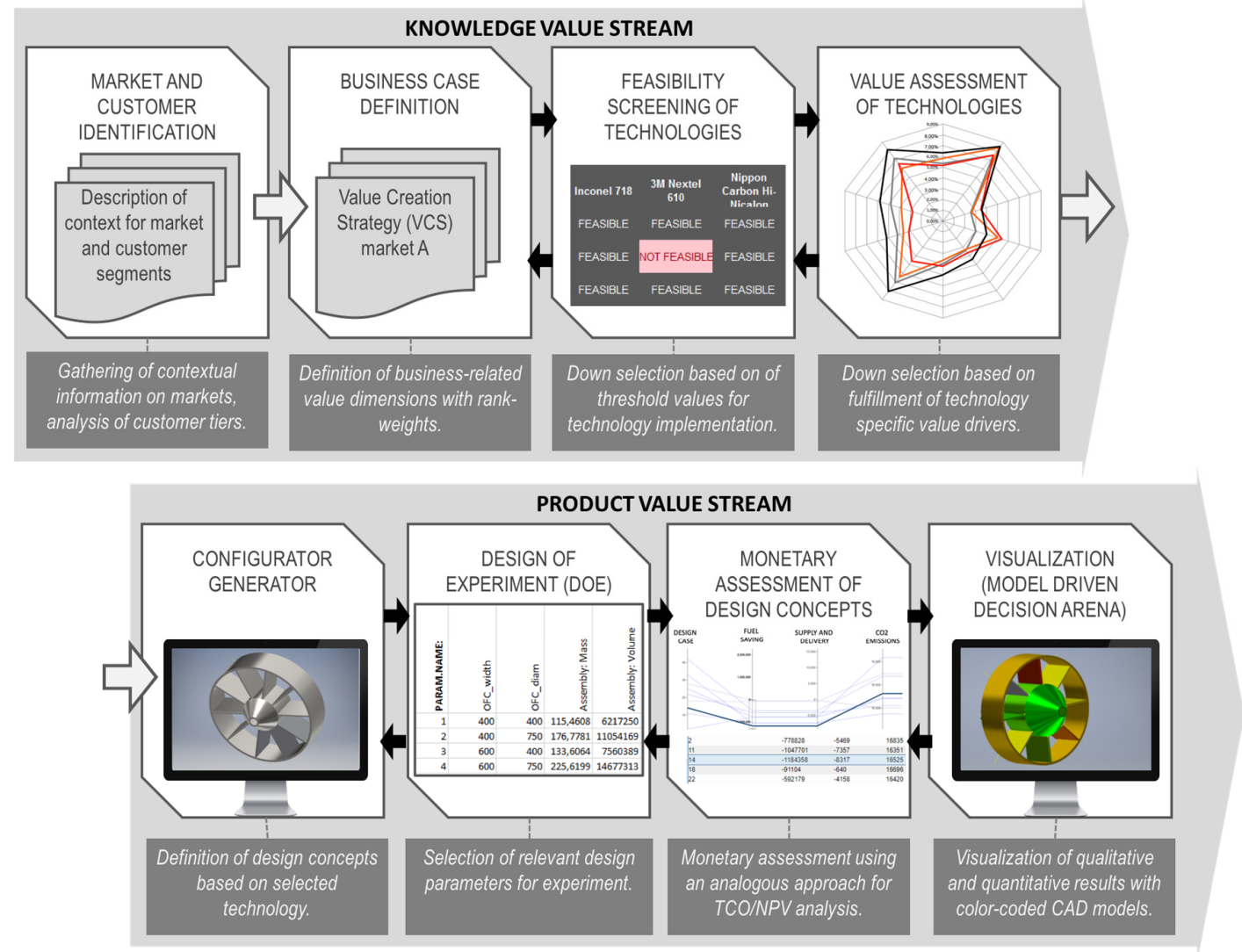

Figure 1. The overall logic of the MDDA

\subsection{Case study: Design of an aero-engine turbine rear structure}

The MDDA was developed and applied in a case study related to the design of a turbine real structure (TRS) for a commercial aircraft engine. This sub-system is dedicated to transferring different loads and redirecting the aero-engine outgoing airflow. Thermal, pressure, and fluid dynamics performances are key design drivers of a TRS.

The objective of the case study was to create value models for a multitude of automatically generated variations of a similar sub-system (in this paper referred as 'concept'), building on the output of computer-based simulations. Even if the technical performances of hundreds of design configurations 
could be analytically predicted quite early, it was not intuitive how to measure their effect on cost and value related aspects. A value assessment routine was needed to run quick what-if analysis and visualize the effects generated by a multitude of small design variations, such as, for instance, changing the angle or the thickness of a flange. In such a complex system, even the smallest design variation might have a noticeable influence on the overall performances, as well as on operational and manufacturing cost.

\subsection{Technology options down-selection in the Knowledge Value Stream}

The purpose of KVS activities is that of reviewing all relevant aspects of value for a technology, including customers, market, and business case. The process kicks-off by identifying customers and markets for potential solutions. A Value Creation Strategy approach (VCS, see Isaksson et al., 2013) is a preferred means to model expectations and preferences of a technology. The VCS contains linearly independent 'value dimensions' that are distilled from the Voice of the Customer and from the manufacturer's wishes and wants. From this description, more detailed metrics can be developed and applied to rate technological options.

In the TRS case study, the VCS is composed of 6 main dimensions (see Figure 2): Aircraft Operations, Emissions, and Servicing reflect the customer point of view, while Development Efficiency, Risk and Production Efficiency are value aspects prioritized from a manufacturer perspective.
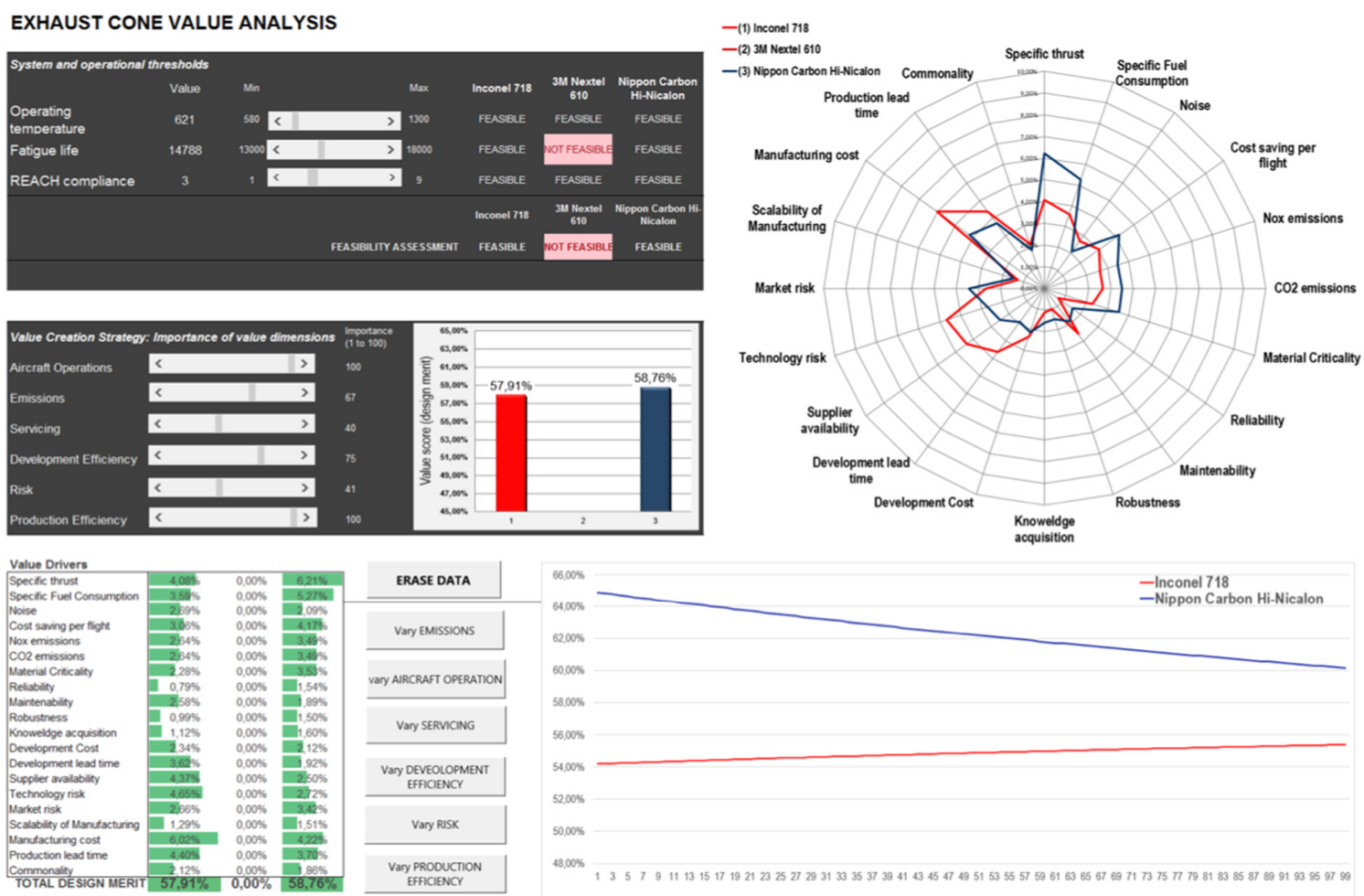

Figure 2. Qualitative value modeling interface

Prior to this evaluation, arena users are asked to conduct a preliminary screening of candidate technologies, with the objective of filtering out options that do not fulfill basic operational or environmental constraints. The top left box of Figure 2 exemplifies how this screening is performed on 3 material choices for TRS exhaust cone application: Inconel 718, 3M Nextel 610 and Nippon-Carbon High Nicalon. The applicability range of these materials varies in terms of Operating temperature, Fatigue life, and compliance with REACH material regulations. In the example, 3M Nextel 610 does not fulfill the fatigue life constraint for the chosen scenario, hence is excluded from the list of candidate solutions for assessment.

The remaining 2 options are assessed qualitatively using a Multi Criteria Decision Analysis (MCDA) approach. This is based on a list of 20 specific value drivers for the solution originating from the VCS 
description. While MCDA can be conducted with a variety of tools, for well-specified technology platforms (such as the TRS), approaches such as the CODA (Eres et al., 2014) and EVOKE (Bertoni et al., 2016) can be adopted. They are designed to reduce personal biases in the MCDA exercise and to better approximate customers' and stakeholders' satisfaction at varying technology attributes, thanks to the use of non-linear value functions. In this example, EVOKE was used to render value scores (expressed in percentage) for each value driver for both the Inconel 718 and Nippon-Carbon High Nicalon options. These scores were further displayed by means of a spider chart and then aggregated to obtain a unique total value score.

The environment provides capabilities to further assess the sensitivity of this total score with regards to changes in the VCS. Using Visual Basic scripts in MS Excel is then possible to plot the total score of each option at varying rank weights. Figure 2 (bottom-right corner) shows that, when the weight of Risk increases in the decision, the value of Nippon-Carbon High Nicalon decreases, together with Inconel 712 becoming more appealing, due better knowledge of the latter. When a satisfying combination of characteristics is found, the team must decide whether to invest resources in optimizing such a combination and to proceed development activities in the PVS or to continue working on critical areas of the system that necessitate higher value contribution.

\subsection{Design concepts evaluation in the Product Value Stream}

Figure 3 describes the detailed logic of the model-driven decision arena in the PVS.

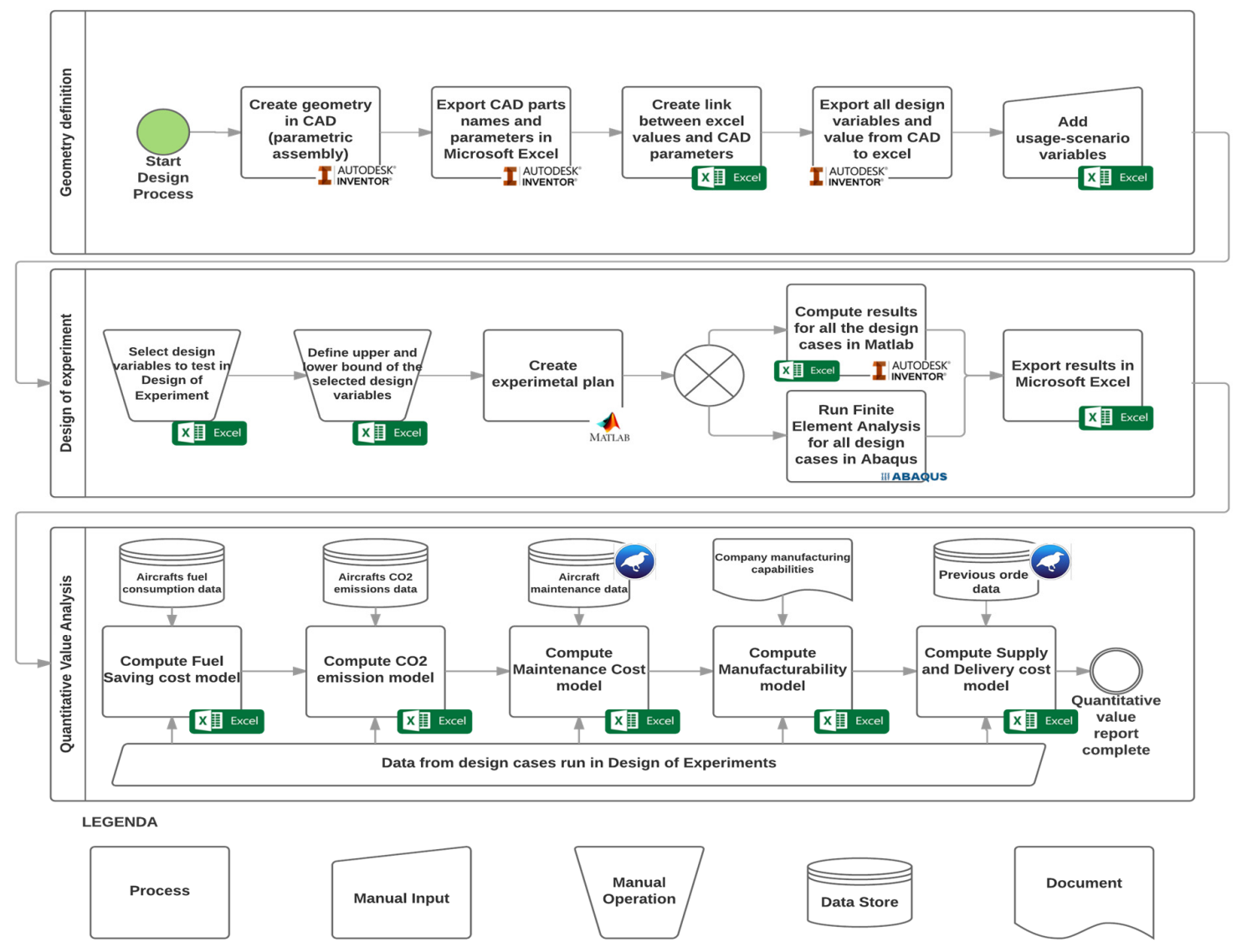

Figure 3. Value assessment procedure in the PVS

The input to the value assessment activities in the PVS is a data structure where design attributes are hierarchically linked to a CAD model of the studied design concept. This CAD model, digitally storing much of the design information, is feature based and parametric, i.e. it is defined by dimensional, geometric and algebraic constraints. A parametric CAD model allows for efficient modification and 
reuse of a given baseline design, generating variants of that baseline by changing parameter values (nongeometric features). Design attributes in the data structure are derived either directly from the CAD model, such as component mass or weld lengths in an assembly, or through engineering models (for example in the form of differential equations, algebraic equations, and mathematical logic). In the case where attributes are derived from engineering models, most data needed to populate those models are attained from the CAD model. An example of such a model is a weld analysis, where necessary weld throat thickness is estimated considering required component life, geometric description, and load case. The proposed simulation process further implements an automated Design-of-Experiment (DoE) tool for the exploration of the design space. When the CAD model is created, design parameters intended to be selectable as design variables in the DoE are defined. After importing design data from the CAD model, a list containing all selectable variables are automatically generated in a GUI and the user may define which of them to include in the DoE study. The next step is to define a usage scenario and choose the parameters to be varied in the study. After that all variables and their bounds are set, an appropriate sampling technique to generate the experimental plan is selected and the experiment is executed. When the experiment is executed, associated attributes for all concept variants in the DoE generated experimental plan are predicted and stored in a database.

\subsubsection{Quantitative value analysis}

The DoE is followed by the development of a cost-saving and revenue-generating function to estimate the economic benefits of new design in different operative scenarios. The quantitative value analysis encompasses five main models assessing value, cost and industrial feasibility of several design cases. Initially, all these models insist on a conceptual approach (Gupta, 1983), based on a set of hypothesized relationships expressed in a qualitative framework. Models are iterated as far as the product description evolves and data is obtained from increasingly refined functional and analytical models.

The Fuel saving cost model renders a relative fuel consumption prediction in form of a delta given a baseline design. In an initial phase, the mass of a given design configuration is used to calculate the relative weight reduction for the proposed TRS sub-system. This result is coupled to a system of multipliers to estimate the overall impact of the aircraft weight reduction. The estimation of fuel saved is then run by deriving aircraft fuel consumption profiles from the data available in the ICAO database (ICAO, 2017) and applying regression analysis to derived fuel consumption functions. CO2 emission calculation is also conducted based on the results of the fuel-saving model and considers that each $\mathrm{kg}$ of aircraft fuel burned produces on average $3.26 \mathrm{~kg}$ of CO2 (ICAO, 2017).

Maintenance costs are based on the parametric cost model proposed by Seemann et al. (2011), which considers shop visit cost (i.e., with the engine detached from the wing, i.e., excluding on-wing maintenance) as a variable of restoration cost (which is linked to the severity of the operational severity), and life limited parts cost (which is, instead, independent from operational context). Assuming operational severity (e.g., take-off thrust) not being impacted by the new component design, it is possible to estimate maintenance cost only based on life-limited component cost. The latter, in turn, can be computed as a function of engine weight, an input obtained from the Fuel savings cost model.

The manufacturing model estimates both the feasibility of manufacturing technologies and potential manufacturing cost. The model uses welding length and thickness to verify the most feasible and convenient welding technologies for a given design configuration. Welding dimensions are also used to estimate the time to weld each concept based on the feasible technology. The cost is then calculated by applying a 'cost per minute' factor for the welding process, which is obtained from industrial practices and that considers machine availability. Furthermore, the model calculates the differences in material prices given the material mass of a design. This is obtained by linearly correlating the mass of a design configuration and the expected percentage of scrap with the market price of the raw material.

A casting cost model is also implemented based on the method proposed by Chougule and Ravi (2006) and is composed of 5 sub-modules: material, energy, tooling, plant and overhead costs. Material cost and energy cost are computed based on mass. The cost of tooling is based on 'cube surface area' of the component in relation to the core complexity (Chougule and Ravi, 2006). Plant and overhead costs are obtained by applying Activity Based Costing to calculate machine cost per year, utilization rate, and labor cost. Eventually, a third manufacturing technology, which is additive manufacturing, is also 
assessed for feasibility and value. The cost model logic is similar to the one described above for casting, and results are eventually benchmarked to identify the most viable manufacturing option.

In the last step, a Supply and delivery cost model is proposed to forecast the expected cost incurred in case of ordering the component from a supplier. Inputs to this model are obtained by applying machine learning algorithms on a historical data from, to investigate the impact of a specific geometrical feature to the final cost of delivery. Each entry in the supplier database records price, delivery cost, delivery time and other information about the order. Each entry is coupled with more specific geometrical data describing the characteristics of the product being purchased. The result of the algorithm is a mathematical function predicting the cost of the supply based on the geometrical feature of a given design configuration. Due to the absence of historical data about deliveries, in the TRS case study presented in this paper this cost evaluation model has been based on an artificially constructed database.

\subsection{Navigating the MDDA environment}

Figure 4 shows the main modules being visualized by the MDDA at decision gate events. These include the $3 \mathrm{D}$ geometry for the given design case, the results of the qualitative and quantitative value assessment models, the color-coded visualization of the latter, and the control panel for parameters selection in the DoE.

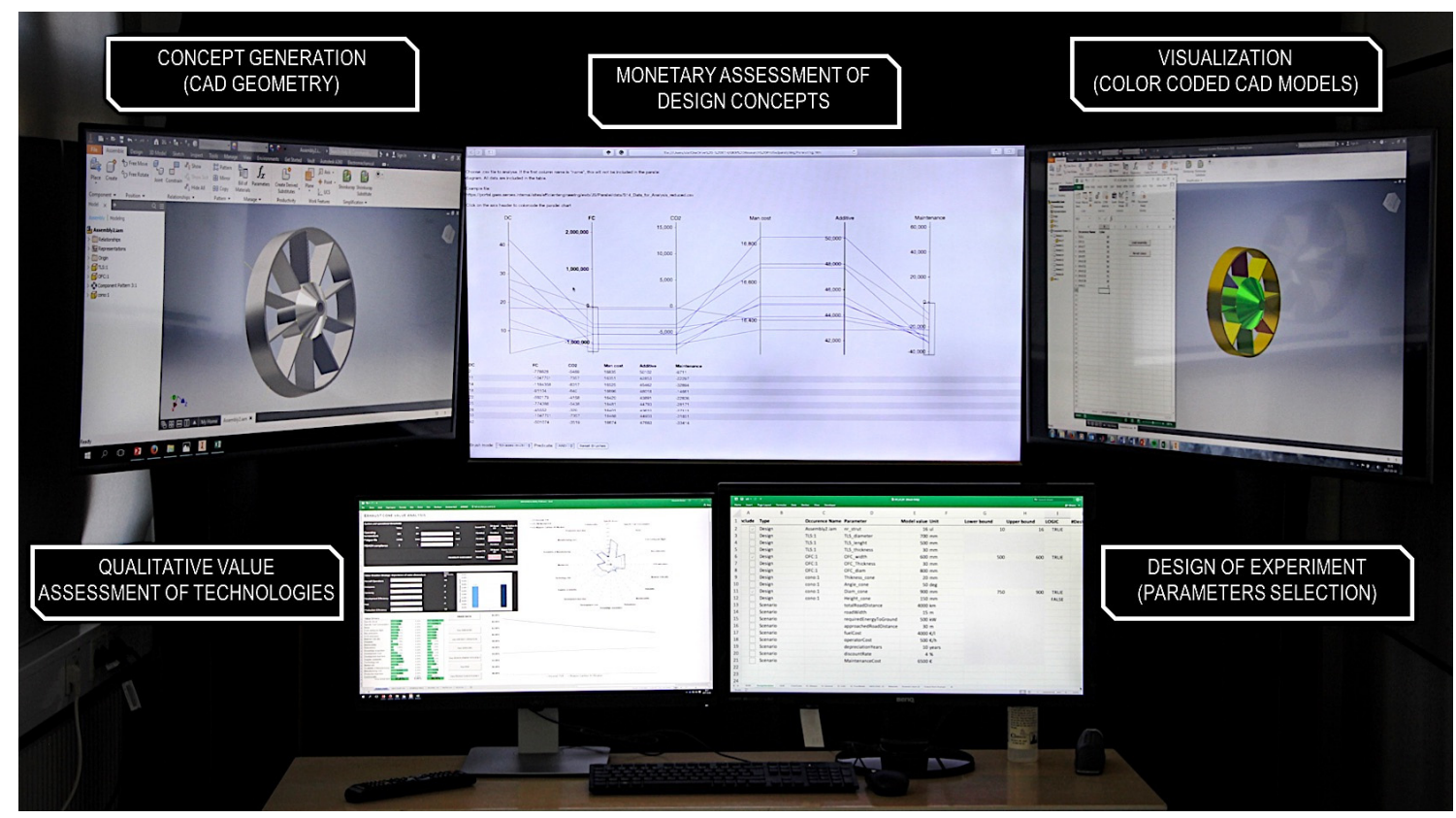

Figure 4. Model-Driven Decision Arena in action

Importantly, the MDDA provides decision makers with ad-hoc interfaces to explore the behavior of given configurations under varying assumptions. These interfaces allow the design team participants to play with some of the model inputs, such average flight range, number of flights per year, number of engines and other relevant scenario parameters. In the proposed case study, of the initial 50 design cases defined in the DoE module, only those showing significant delta savings for fuel cost or maintenance, were considered for further analysis. The selected configurations are then further detailed using functional modeling techniques, and target requirements are set for each specific constituting part. Parallel coordinates support the design team with this set-based engineering exercise, identifying limits and restrains, and excluding non-viable and non-sustainable solutions. A main reason for employing parallel coordinates is that respondents expressed a preference for having not only the final TCO figure to be visualized, but to be also able to understand its main constituting items as well as the system performances that drives them: "you want an end result but still you want to keep track of why it is like that". 
Another main feature of the MDDA is its ability to exploit color-coded CAD models to improve visualization of the value assessment results. As expressed during the descriptive study: "to be confident in this kind of a decision support, you need to understand. A way to make this easy is that you do this clearly and visually". Simulation results and value scores are therefore mapped to a color scale to highlight components/variables that are negatively or positively affected by a new design. The main advantage in linking geometrical and cost data in the same graphical representation is that crossfunctional team participants do neither need to know the specific terminology, nor struggle to abstract the results of a specific domain model, thus making it easier to interact. A color scale ranging from green through yellow to red is used. This color scheme, where green is good and red is bad for the studied objective, is believed to be intuitive to the end-user making it approachable and understandable also for non-experts. Presenting results this way enables the design team to identify trade-offs and follow cause and effect relations through the model hierarchy.

\section{Discussion}

A challenge in MDDA development is not only about producing data or results, but rather to make the data interpretable and understandable in a wider community. This implies an effort to make the cause and effect chain to be understandable so that decision-makers can reach consensus on what happens and why, and what direction needs to be taken in decision events. Hence, one of the most urgent research areas for the MDDA is related to the generation of guidelines on how to interact with the environment without the need to possess expert knowledge. For instance, it is not clear to what extent the crossfunctional team shall be able to play with scenario variables (fuel consumption, flight range, etc.), and how much these descriptions shall be automated vs. fully modifiable.

Several technical challenges have also emerged during the construction of the environment. The realization of the MDDA mock-up showed that a great deal of expert knowledge is needed to configure the system for each specific case study. Interlinking models is a labor-intensive activity, requiring specific skills to connect heterogeneous domain and software. Hence, future work will be focused on the development of a standard approach in model communication, in terms of specifying interfaces to enable a seamless exchange of inputs-outputs between models.

Robustness and speed of execution are also main challenges. Preliminary verification activities showed that, during decision gate meetings, the MDDA results at each iteration (i.e., for each change in the input parameters) need to be communicated to the team almost instantaneously. Error messages, or even a lag of few seconds during the computation process, might spoil the discussion and negatively impact knowledge sharing. More than an issue of pure computing power, this is a problem of developing efficient schemes on how to produce data for the visualization, and how to manage them to enable a real-time experience when playing with design concepts. A way forward currently explored is the use of machine learning (partly already introduced in the MDDA, as described above) to create surrogate models that could reduce computational time. This is particularly important when working with computationally-heavy simulations, e.g., FEM analysis, etc. Being the purpose that of creating awareness and consensus on solution directions, rather than that of 'engineering' a system, the trade-off between precision and speed in the MDA computational process is resolved in favor of the latter.

As a side note, working with color-coding, it is important to keep in mind that several individuals suffer from problems with recognition and understanding of colorful images and videos. These can be addressed by running an appropriate re-coloring algorithm, a method of altering the color composition of an image to make it accessible to a color vision impaired audience (Kuhn et al., 2008). Re-coloring algorithms, although not yet implemented in the current demonstrator, are expected to be an integral part of the future full-scale prototype.

\section{Conclusions}

Creating an environment where the cross-functional team can visually link value to design configurations is a necessary step towards enabling more value-oriented decisions in design. The main function of the MDDA is therefore to support the systematic evaluation of early stage design concepts in a way that goes beyond the requirement description. This raised awareness shall facilitate negotiation of system features across organizational functions and roles. Harvesting potential interaction between 
domains, and growing consensus on where design intent is heading, can reduce rework that originates from misinterpretations of requirements and sub-optimal designs. Still, a systematic approach shall not impede transparency and trustability. The underlying logic of a concept selection model shall be understood outside the specific role of the system engineer so that all knowledge owners across the lifecycle (possibly from different organizations) can contribute to the definition of value-adding solutions.

The vision for the MDDA is that the design team shall be able to set up and run the environment with minimal expert support. For this reason, future research will feature 'few-focused case studies', to grow lessons learned about which MDDA building blocks can be generalized and reused, vs. those that need to be customized for each case. Future research will also aim at experimentally verifying the use of the MDDA, gathering more factual by analytically observing the designers' cognitive behavior in design episodes, using the thinking aloud method (Gero and Mc Neill, 1998). These observations will also help in ensuring the seamless integration of the MDDA in daily work practices. Previous contributions (e.g., Engelbrektsson and Söderman, 2004) have shown how design practitioners are often accustomed to and effective with existing representations and tools when dealing with design decision making. Future research will need to consider how the MDDA shall be integrated with existing solutions to avoid breaking the chain of analysis processes.

\section{Acknowledgments}

The research leading to these results has received financial support by the Swedish Knowledge and Competence Development Foundation (Stiftelsen för kunskaps- och kompetensutveckling) through the Model Driven Development and Decision Support research profile at Blekinge Institute of Technology. The work has also been performed with financial support from Swedish Governmental Agency for Innovation Systems (VINNOVA), in the frame of the NFFP VITUM project.

\section{References}

Avison, D., Lau, F., Myers, M. and Nielsen, P.A. (1999), “Action Research”, Communications of the ACM, Vol. 42 No. 1, pp. 94-97. https://doi.org/10.1145/291469.291479

Baines, T.S., Lightfoot, H.W., Evans, S., Neely, A., Greenough, R. et al. (2007), "State-of-the-Art in ProductService Systems", Journal of Manufacturing Engineering, Vol. 221 No. 10, pp. 1543-1552. https://doi.org/10.1243/09544054JEM858

Bertoni, A. (2013), “Analyzing Product-Service Systems conceptual design: The effect of color-coded 3D representation”, Design Studies, Vol. 34 No. 6, pp. 763-793. https://doi.org/10.1016/j.destud.2013.02.003

Bertoni, M. and Bertoni, A. (2016), "Models for Value-driven engineering design", Proceedings of the DESIGN 2004 / 14th International Design Conference, Dubrovnik, Croatia, May 16 - 19, 2016, The Design Society, Glasgow, pp. 1195-1204.

Bertoni, M., Bertoni, A. and Isaksson, O. (2018), "Evoke: A value-driven concept selection method for early system design", Journal of Systems Science and Systems Engineering, Vol. 27 No. 1, pp. 46-77. https://doi.org/10.1007/s11518-016-5324-2

Bresciani, S. and Eppler, M.J. (2009), "The benefits of synchronous collaborative information visualization: Evidence from an experimental evaluation", IEEE Transactions on Visualization and Computer Graphics, Vol. 15 No. 6, pp. 1073-1080. https://doi.org/10.1109/TVCG.2009.188

Cheung, J., Scanlan, J., Wong, J., Forrester, J., Eres, H. et al. (2012), “Application of value-driven design to commercial aeroengine systems", Journal of Aircraft, Vol. 49 No. 3, pp. 688-702. https://doi.org/10.2514/1.C031319

Chougule, R.G. and Ravi, B. (2006), "Casting cost estimation in an integrated product and process design environment”, International Journal of Computer Integrated Manufacturing, Vol. 19 No. 7, pp. 676-688. https://doi.org/10.1080/09511920500324605

Collopy, P.D. (2012), “A Research Agenda for the Coming Renaissance in Systems Engineering”, Proceedings of the 50th AIAA Aerospace Sciences Meeting including the New Horizons Forum and Aerospace Exposition, Nashville, Tennessee, January 9-12, 2012, American Institute of Aeronautics and Astronautics, Reston, pp. 11775-11784. https://doi.org/10.2514/6.2012-799

Collopy, P.D. and Hollingsworth, P.M. (2011), "Value-driven design", Journal of Aircraft, Vol. 48 No. 3, pp. 749759. https://doi.org/10.2514/1.C000311 
Coughlan, P. and Coghlan, D. (2002), “Action research for operations management”, International Journal of Operations \& Production Management, Vol. 22 No. 2, pp. 220-240. https://doi.org/10.1108/01443570210417515

Curran, R., van der Zwan, F., Ouwehand, A. and Ghijs, S. (2010), "Value analysis of engine maintenance scheduling relative to fuel burn and minimal operating costs", Proceedings of ATIO 2010 / the 10th AIAA Aviation Technology, Integration, and Operations Conference, Fort Worth, Texas, September 13-15, 2010, American Institute of Aeronautics and Astronautics, Reston, pp. 895-901. https://doi.org/10.2514/6.2010-9145

Endsley, M.R. (1995), "Toward a theory of situation awareness in dynamic systems", Human factors, Vol. 37 No. 1, pp. 32-64. https://doi.org/10.1518/001872095779049543

Engelbrektsson, P. and Söderman, M. (2004), "The use and perception of methods and product representations in product development: A survey of Swedish industry”, Journal of Engineering Design, Vol. 15 No. 2, pp. 141154. https://doi.org/10.1080/09544820310001641245

Eres, M.H., Bertoni, M., Kossmann, M. and Scanlan, J. (2014), "Mapping customer needs to engineering characteristics: an aerospace perspective for conceptual design", Journal of Engineering Design, Vol. 25 No. 1-3, pp. 64-87. https://doi.org/10.1080/09544828.2014.903387

Fan, M., Vittal, V., Heydt, G.T. and Ayyanar, R. (2012), "Probabilistic power flow studies for transmission systems with photovoltaic generation using cumulants", IEEE Transactions on Power Systems, Vol. 27 No. 4, pp. 2251-2261. https://doi.org/10.1109/TPWRS.2012.2190533

Fanthorpe, C., Soban, D., Price, M. and Butterfield, J. (2011), "Developing a capability function relating aircraft systems cost overruns to aircraft design parameters", Proceedings of ATIO 2011 / the 11th AIAA Aviation Technology, Integration, and Operations Conference, Vol. 1, Virginia Beach, September 20-22, 2011, American Institute of Aeronautics and Astronautics, Reston, pp. 491-506. https://doi.org/10.2514/6.2011-6837

Gero, J.S. and Mc Neill, T. (1998), “An approach to the analysis of design protocols”, Design Studies, Vol. 19 No. 1, pp. 21-61. https://doi.org/10.1016/S0142-694X(97)00015-X

Gorissen, D., Quaranta, E., Ferraro, M., Schumann, B., Van Schaik, J. et al. (2014), "Value-Based Decision Environment: Vision and Application", Journal of Aircraft, Vol. 51 No. 5, pp. 1360-1372. https://doi.org/10.2514/1.C032153

Gupta, Y.P. (1983), "Life cycle cost models and associated uncertainties”, In: Skwirzinsky, J.K. (Ed.), Electronic Systems Effectiveness and Life Cycle Costing, Springer, Berlin, Heidelberg, pp. 535-549. https://doi.org/10.1007/978-3-642-82014-4_29

Harrison, A. (2006), "Design for service - Harmonising product design with a services strategy", Proceedings of the ASME Turbo Expo 2006: Power for Land, Sea, and Air, Barcelona, Spain, May 8-11, 2006, ASME, pp. 135-143. https://doi.org/10.1115/GT2006-90570

Hazelrigg, G.A. (1998), "A framework for decision-based engineering design”, Journal of Mechanical Design, Vol. 120 No. 4, pp. 653-658. https://doi.org/10.1115/1.2829328

ICAO (2017), ICAO Carbon Emissions Calculation Methodology, Version 10. [online] ICAO. Available at: https://www.icao.int/environmental-protection/CarbonOffset/Documents/Methodology\%20ICAO\%20Carbon $\% 20$ Calculator_v10-2017.pdf

Isaksson, O., Bertoni, M., Hallstedt, S. and Lavesson, N. (2015), "Model Based Decision Support for Value and Sustainability in Product Development", Proceedings of ICED'15 / the 20th International Conference on Engineering Design, Vol. 1, Milano, Italy, July 27-31, 2015, The Design Society, Glasgow, pp. 21-30.

Isaksson, O., Kossmann, M., Bertoni, M., Eres, H., Monceaux, A. et al. (2013), "Value-Driven Design-A methodology to Link Expectations to Technical Requirements in the Extended Enterprise", INCOSE International Symposium, Vol. 23 No. 1, pp. 803-819. https://doi.org/10.1002/j.2334-5837.2013.tb03055.x

Isaksson, O., Larsson, T.C. and Rönnbäck, A.Ö. (2009), "Development of product-service systems: challenges and opportunities for the manufacturing firm”, Journal of Engineering Design, Vol. 20 No. 4, pp. 329-348. https://doi.org/10.1080/09544820903152663

Kennedy, M., Harmon, K. and Minnock, E. (2008), Ready, set, dominate - Implement Toyota's Set-Based Learning for Developing Products and Nobody Can Catch You, The Oaklea Press, Richmond.

Kuhn, G.R., Oliveira, M.M. and Fernandes, L.A. (2008), "An efficient naturalness-preserving image-recoloring method for dichromats", IEEE Transactions on Visualization and Computer Graphics, Vol. 14 No. 6, pp. 17471754. https://doi.org/10.1109/TVCG.2008.112

Larsson, A., Ericson, Å., Larsson, T., Isaksson, O. and Bertoni, M. (2010), "Engineering 2.0: Exploring lightweight technologies for the virtual enterprise", In: Randall, D. and Salembier, P. (Eds.): From CSCW to Web 2.0: European Developments in Collaborative Design, Springer, London, pp. 173-191. https://doi.org/10.1007/978-1-84882-965-7 9

McManus, H.M., Richards, M.G., Ross, A.M., Hastings, D.E. (2007), “A Framework for Incorporating "ilities" in Tradespace Studies", Proceedings of the AIAA SPACE 2007 Conference \& Exposition, Vol. 1, Long Beach, 
California, September 18-20, 2007, American Institute of Aeronautics and Astronautics, Reston, pp. 941-954. https://doi.org/10.2514/6.2007-6100

Minneman, S.L. (1991), The social construction of a technical reality: empirical studies of group engineering design practice, $\mathrm{PhD}$ thesis, Stanford University.

Price, M., Soban, D., Mullan, C., Butterfield, J. and Murphy, A. (2012), "A novel method to enable trade-offs across the whole product life of an aircraft using value driven design", Journal of Aerospace Operations, Vol. 1 No. 4, pp. 359-375. https://doi.org/10.3233/AOP-120028

Roosenburg, N.F.M. and Eekels, J. (1995), Product Design: Fundamentals and Methods, John Wiley \& Sons, Chichester.

Runnemalm, H., Tersing, H. and Isaksson, O. (2009), "Virtual manufacturing of light weight aero engine components", Proceedings of ISABE 2009 / the 19th International Symposium on Air Breathing Engines, Vol. 1, Montreal, Canada, September 7-11, 2009, American Institute of Aeronautics and Astronautics, pp. 170-176.

Sampson, D.A., Escobar, V., Tschudi, M.K., Lant, T. and Gober, P. (2011), “A provider-based water planning and management model-WaterSim 4.0-For the Phoenix Metropolitan Area", Journal of Environmental Management, Vol. 92 No. 10, pp. 2596-2610. https://doi.org/10.1016/j.jenvman.2011.05.032

Sedlmair, M., Isenberg, P., Baur, D. and Butz, A. (2011), "Information visualization evaluation in large companies: Challenges, experiences and recommendations", Information Visualization, Vol. 10 No. 3, pp. 248-266. https://doi.org/10.1177/1473871611413099

Seemann, R., Langhans, S., Schilling, T. and Gollnick, V. (2011), "Modeling the life cycle cost of jet engine maintenance", 60. Deutscher Luft- und Raumfahrtkongress, Bremen, September 27-29, 2011, DGLR, Bonn.

Severin, W. (1967), "Another look at cue summation", AV Communication Review, Vol. 15 No. 3, pp. $233-245$.

Siyam, G.I., Wynn, D.C. and Clarkson, P.J. (2015), "Review of value and lean in complex product development", Systems Engineering, Vol. 18 No. 2, pp. 192-207. https://doi.org/10.1002/sys.21299

Soban, D.S., Price, M.A. and Hollingsworth, P. (2012), "Defining a research agenda in Value Driven Design: Questions that need to be asked", Journal of Aerospace Operations, Vol. 1 No. 4, pp. 329-342. https://doi.org/10.3233/AOP-120026

Söderberg, R., Lindkvist, L. and Carlson, J. (2006), "Virtual Geometry Assurance for Effective Product Realization", Proceedings of NordPLM'06 / the 1st Nordic Conference on Product Lifecycle Management, Göteborg, Sweden, January 25-26, 2006.

Tegarden, D.P. (1999), "Business information visualization”, Communications of the AIS, Vol. 1 No. 1.

Thomke, S. and Fujimoto, T. (2000), "The effect of "front-loading" problem-solving on product development performance", Journal of Product Innovation Management, Vol. 17 No. 2, pp. 128-142. https://doi.org/10.1016/S0737-6782(99)00031-4

Vallhagen, J., Isaksson, O., Söderberg, R. and Wärmefjord, K. (2013), “A framework for producibility and design for manufacturing requirements in a system engineering context", Procedia CIRP, Vol. 11, pp. 145-150. https://doi.org/10.1016/j.procir.2013.07.041

Weiss, S.I. (2013), Product and Systems Development: A Value Approach, John Wiley \& Sons, Hoboken. https://doi.org/10.1002/9781118592977

Yin, R.K. (2013), Case study research: Design and methods, Sage publications, Thousand Oaks.

Marco Bertoni, Associate Professor

Blekinge Institute of Technology

SE-371 79 Karlskrona, Sweden

Email: marco.bertoni@bth.se 